\title{
Evolution Education in Utah: A State Office of Education-University Partnership Focuses on Why Evolution Matters
}

\author{
Jerald B. Johnson • Marta Adair • Byron J. Adams • Daniel J. Fairbanks • \\ Velma Itamura • Duane E. Jeffery • Duane Merrell • Scott M. Ritter • \\ Richard R. Tolman
}

Published online: 2 July 2009

(C) Springer Science + Business Media, LLC 2009

\begin{abstract}
Several groups of people are essential for effectively teaching the theory of evolution in public schools. Teachers of course are at the leading edge of educating students. However, school district administrators, school boards, state education officers, and university professors all play critical roles in this endeavor. Whereas scientific discoveries and teacher training typically occur at the university level, it is school district leaders and teachers who actually disseminate this information in a way that creates an educated population of students. In this study, we introduce a partnership focused on strengthening evolution education in Utah's public schools. Our program centers on the importance of evolution as an applied science and one
\end{abstract}

\author{
J. B. Johnson $(\bowtie) \cdot$ M. Adair $\cdot$ B. J. Adams $\cdot$ D. E. Jeffery \\ Department of Biology, Brigham Young University, \\ Provo, UT 84602, USA \\ e-mail: jerry.johnson@byu.edu \\ S. M. Ritter \\ Department of Geological Sciences, Brigham Young University, \\ Provo, UT 84602, USA \\ D. Merrell \\ Department of Physics, Brigham Young University, \\ Provo, UT 84602, USA \\ J. B. Johnson $\cdot$ M. Adair \\ Monte L. Bean Life Science Museum, Brigham Young University, \\ Provo, UT 84602, USA \\ D. J. Fairbanks $\cdot$ R. R. Tolman \\ Department of Biology, Utah Valley University, \\ Orem, UT 84058, USA \\ V. Itamura \\ Utah State Office of Education, \\ Salt Lake City, UT 84112, USA
}

that can be readily integrated throughout the biology curriculum. Our 2-day workshop-conducted in each Utah school district-brings together elected school board members, school district administrators, public school science teachers, and university professors to overcome barriers that can arise when teaching the theory of evolution as part of the 7-12 public school curriculum.

Keywords In-service training - Professional development . School board $\cdot$ University-public school partnership

\section{Introduction}

A fundamental tenet of public education is that all students should have equal access to knowledge (Goodlad et al. 2004). This ideal is so foundational that some educators describe it as "a moral dimension" of teaching (Fenstermacher 1990). Indeed, justification for government sponsorship of public education is grounded in the idea that access to knowledge strengthens societies, empowers individuals in their pursuit of well-being, and leads to advances that fundamentally improve national competitiveness and the collective human condition (Feinberg 1990; Goodlad et al. 2004). Not surprisingly, most contemporary efforts at educational reform-particularly in democratic societies - are closely linked to the view that access to knowledge is a basic right, without respect to race, national origin, religion, economic status, or geography (e.g., United States Public Law 107-110 2001).

Perhaps no knowledge in biology is as important as the theory of evolution as an explanation of the history and diversity of life on earth. Yet efforts to teach students the theory of evolution are often undermined by a variety of 
biases (Ayala 2007; Collins 2006; National Academy of Sciences (U.S.) 1999; National Academy of Sciences (U.S.) and Institute of Medicine (U.S.) 2008; Branch and Scott 2008). In the USA for example, some students are much more likely than others to receive rigorous training in evolutionary biology, with pronounced differences in terms of geography (Pew Forum on Religion and Public Life 2008). Unfortunately, it remains a general truism that where a student lives largely dictates the extent to which she or he will be taught the fundamental principles of evolution. The question is: why does this matter? Unfortunately, the cost of omission, or insufficient coverage of evolution in public science education is not readily apparent to most members of the educational community, and fewer still in the general public understand why it is important to teach the theory of evolution.

In this paper, we describe an effort to ensure that students throughout the state of Utah have sufficient access in public schools to knowledge of the theory of evolution. This effort is the result of a unique partnership between the Utah State Office of Education, school districts throughout the state, and a group of university professors. Our objective is to support evolution education in each school district in the state by working directly with school administrators and science teachers who teach grades 712 earth science and biology curricula. We conduct a 2-day workshop focused on foundational principles of evolution and why they matter. In this article, we describe this ongoing program, including the curriculum we use to support evolution education in Utah.

\section{Background and Motivation for Outreach}

The State of Utah has one of the strongest sets of science standards in the USA; these standards explicitly call for the inclusion of the theory of evolution in the public education science curriculum (http://www.schools.utah.gov/curr/sci/ evolution.htm). Yet there is a general perception in the public that evolutionary biology contradicts valid religious beliefs and is of limited utility in practical human endeavors (Pew Forum on Religion and Public Life 2008). Moreover, some political forces in the State of Utah have questioned the theory of evolution and have attempted through legislation to force non-scientific alternatives to be included in the public school science curriculum (Amended evolution measure dies in Utah House. http://www.deseretnews. com/article/1,5143,635188017,00.html). These political maneuvers, although not successful in their legislative efforts, have created an opportunity for scientists, public school educators, and the general public to consider the merits of the theory of evolution and more particularly to consider why access to this knowledge matters. In response to this opportunity, the Utah State Office of Education has funded a program dedicated to supporting the state science standards in Utah classrooms and to strengthening ties between university scientists and public educators. The program described here is the outcome of that effort.

\section{Utah Evolution Education Program}

The Utah Evolution Education Program is a partnership between the Utah State Office of Education, individual school districts throughout the state, and a group of seven university professors with backgrounds in evolutionary biology, genetics, and geology. Our primary goal is to provide resources to teachers as they apply the state science standards in biology and earth systems, both of which rely on knowledge of the theory of evolution. Beyond this, our efforts are focused on creating a forum in which school boards, public school administrators, public school teachers, and our university team can openly discuss concerns and challenges to teaching evolution in each respective school district. Finally, our program is designed to empower public school teachers with recent advances in evolutionary biology that can be integrated into their curricula and that clearly illustrate the value of evolutionary biology as a theory with practical applications to improve the human condition. In short, our approach is to show all members of the public school community-including elected school boards, administrators, public school teachers, and ultimately students - what evolution is and why it matters.

The state of Utah is divided into 41 school districts. Our program uses a 2-day workshop format and is designed so that an individual workshop can be conducted in each school district. In some rural areas, two or more districts might be combined, but our intent is to keep these workshops small in size and focused on specific needs unique to each area; for example, challenges faced by large urban school districts tend to be different from those in smaller, rural districts. Workshops are sanctioned through the Utah State Office of Education and are coordinated with each school district. School districts typically invite all participants, including school board members, administrators, and science teachers for the first evening of the workshop, and grade 7-12 science teachers for the second full day of the workshop. Districts also designate the second day of the workshop as a professional development event and provide substitute teachers to allow one full day of participation by science teachers. The core group of facilitators and presenters includes seven university professors and the state Office of Education science specialist. Prior to each workshop, a member of our team does advance scouting work by communicating with the district science specialist to identify specific evolution-related issues that might warrant special consideration in our 
preparations. Here, we describe how each element of the workshop is conducted, including the curricular material that we cover and how we integrate the relevance of evolutionary theory into our program.

Reaching Out to School Boards and Administrators

School board members in Utah are elected officials. School boards hire school district superintendents, and superintendents hire principals. It is uncommon for any of these individuals to have a formal science background in biology. However, these district leaders provide an important link to the community and are essential stakeholders in determining how effectively the state science standards are implemented. Consequently, the first component of our workshop is to bring together school board members, administrators, and science teachers to discuss how evolution is taught in their school district. We usually do this through an evening event, often over a group meal, which creates an informal setting for discussion.

Our outreach to school district leaders and teachers in the evening meeting focuses on three goals. First, we want participants to understand what evolution is. Second, we want participants to recognize that knowledge of the theory of evolution is highly relevant in a variety of human advances and is essential for our students to master for them to be nationally and internationally competitive in intellectual and economic endeavors. Finally, we want school board members and administrators to understand why teachers should include evolution in their curriculum, and we want teachers to know that their leaders are aware of the state science standards and are supportive of their implementation, particularly with respect to teaching evolution. We use several activities to achieve these goals. We typically set up seven tables so that each small group of school district members can be joined by one of our university presenters. During this time, we define evolution, draw distinctions between evolution (concept of descent with modification) and natural selection as a mechanism of evolutionary change, and explore inaccuracies and accuracies about evolution (e.g., humans descended from chimps versus humans and chimps share a common ancestor). Following this, one member of our team makes a formal presentation focused on the urgency of helping students acquire skills in science literacy as a means of creating a competitive and informed population; the presenter also summarizes the many ways that evolution is applied in contemporary human activities (e.g., medicine, agriculture, forensics, and conservation). We end this event with an open discussion focused on any challenges that teachers or administrators feel with respect to teaching evolution in public schools. This discussion often includes a review of school policies with respect to questions about religion and science, ways to effectively communicate with parents, and ideas about how school board members and administrators can most effectively support quality science instruction by their teachers. This meeting helps to strengthen the partnership between teachers and school leaders.

\section{Evolution Education and Teacher Professional} Development

The second day of our workshop is focused almost completely on professional development of public school teachers. We begin this day with an hour-long presentation reinforcing the importance of teachers as guides in developing the next generation of scientifically literate citizens. We show and discuss trends over time in science and math literacy in Utah and in the United States to underscore the urgency of the work that teachers do. We then divide teachers into smaller groups (typically two to four groups of 20 depending on the number of participants) and invite them to rotate through two sets of breakout sessions. The morning set includes four 30-minute sessions focused on evolutionary applications in the fields of medicine, forensics, agriculture, and conservation biology. The afternoon set includes three 45 -minute sessions. These include a hands-on module focused on teaching biological classification through phylogeny reconstruction, on morphological evidence for human evolution, and on genomic evidence for human evolution. During the noon hour, we provide lunch and present a 50-minute slide show of Charles Darwin's life. Below, we offer a detailed description of each of these breakout sessions; we also discuss ways that the content covered in these sessions might be implemented for use in the classroom.

\section{Applied Evolution: A Theory that Matters}

Why does the theory of evolution matter? Many scientists are satisfied simply by the intellectual pursuit for understanding how the world works. However, the general public often expects science to generate advances that directly improve the human condition. Does the theory of evolution have anything to offer in this regard? In our workshop, we explore four areas where evolution has directly and dramatically been applied in human activities. Our point is to illustrate that without access to knowledge of evolution, humankind would lack several key applications essential to current human well-being. Our list of course is not exhaustive, and how future generations will apply the theory of evolution is an exciting prospect.

Medicine Some of our most important applications of the theory of evolution have occurred in medicine. Classic examples include the evolution of pathogen resistance in 
response to antibiotic or antiviral drugs (Palumbi 2001). More recent application of evolutionary theory to this problem includes the cost of pathogen resistance. By understanding the concept of relative fitness for resistant versus susceptible forms, savvy physicians have been able to devise drug treatment regimens that render infections more amenable to treatment with available drugs (Palumbi 2001). Similar advances have been made in the treatment of viral infections, as viruses evolve in response to the selective effect of the human immune system. In these cases, understanding the evolutionary history of viral strains - through phylogenetic reconstruction-offers important insights into the most promising targets for vaccine development and for predicting epidemic or pandemic spread of emerging viral strains. Innovative treatments targeting the viruses responsible for AIDS, influenza, and the common cold are all firmly anchored in evolutionary theory (e.g., Crandall 1999).

Beyond pathogen evolution, the growing field of "evolutionary medicine" offers insights into several additional questions in human health (Stearns 2005; Abbott 2006; Nesse et al. 2006). Why do people have wisdom teeth? Why is the human birth canal so narrow? Why do we crave fatty foods that in excess are not good for us? Why do people age and why are so many diseases expressed late in life? An answer to each of these questions can be found in evolutionary theory (Nesse and Williams 1994; Nesse et al. 2006). Evolution also offers an explanation for why some pathogens are highly virulent, even causing death, while others are much more benign (Ewald 1991). In short, the full range of human health issues is better understood against an evolutionary backdrop. In our breakout session, we discuss several of these examples and point teachers to the growing literature in evolutionary medicine.

Forensics Many forensic techniques rely on evolutionary concepts. Moreover, popular television shows and highly publicized celebrity trials have produced high levels of student awareness and interest in forensic science. Because some of the most dramatic and compelling forensic evidence arises from genetic analyses that are based on fundamental principles of evolutionary biology, this topic readily lends itself to classroom activities and discussions that address core ideas in evolutionary biology.

We encourage teachers to introduce the topic by engaging students in a brief discussion of a recent case. What is forensic science? Who can provide an example of a crime that was solved by forensic evidence? What were the "facts" associated with the case? At this point, it is instructive to present the text of the Cobb County Board of Education statement "Evolution is a theory, not a fact, regarding the origin of living things" and discuss the different ideas the students have about the relationship between theories and facts. We suggest to teachers that this discussion can naturally segue into a demonstration that "evolution is a fact" (Fitch 2005). Once students understand the semantics of "facts," "hypotheses," and "theories," as well as the logic of thinking of evolution as a fact, we return to the topic of forensics and point out that two evolutionary concepts are currently applied in the United States' courts and accepted as "facts" (Mindell 2005). The first is that different features of our genome evolve at different rates, resulting in each of us having a unique DNA fingerprint. Depending on the preparation of the students, this is often a good time to revisit the mechanics of mutation and selection and why some parts of the genome are highly conserved whereas others are mutational hotspots. The second evolutionary fact applied in the United States' courts is "descent with modification." This is a good place to introduce and emphasize "tree thinking," that what the courts accept as "fact" is a phylogenetic tree. We also suggest to teachers that this is a good place in the discussion to introduce or reinforce the idea that the tree depicts more closely related individuals as sharing more recently derived variants in the DNA sequences or inherited characters than more distant relatives.

After establishing how descent with modification informs tree thinking, we show teachers ways engage their students in analyses of actual case studies (and associated data) to reinforce how fundamental principles of evolution are used to solve crimes. As an exercise, when shown DNA gel electrophoresis diagrams, students can readily associate the different banding patterns with genetic diversity (and identify the perpetrator!; good examples of these are available at http://evolution.berkeley.edu/evolibrary/news/ 060301_crime). Similarly, the explanatory power of phylogenetic trees is well demonstrated by prominent cases of alleged intentional HIV infections (Metzker et al. 2002; de Oliveira et al., 2006) and poaching (Mindell 2005). Emphasis on evolutionary principles empowering justice (http://www.innocenceproject.org/), such as the Roger Keith Coleman and Alan Crotzer cases where DNA evidence was used to evaluate claims of innocence in crimes, captivate student thinking. Students also enjoy discussing cases that involve teenagers using these tools to address their own questions ("What's in my sushi?"; http://www.nytimes.com/ 2008/08/22/science/22fish.html).

Agriculture Perhaps no human endeavor is more broadly impacted by the theory of evolution than modern agriculture. Consequently, several Utah state science standards in biology are well illustrated by focusing on evolutionary applications in agricultural practices (Gepts 2005). One of these standards asks students to compare natural selection to selective breeding and observing changes in genetic traits 
due to natural and human influences. We initiate discussion of this topic by asking "Where does our food come from?" Although the answer "From a farm!" may be reassuring to some, we use their response to explore what the students know about domestication, emphasizing that many of the common animals and plants we use today were domesticated from wild relatives over the last 9,000 years. Using pictures of some of these wild relatives and scenarios that involve looking at the variation in traits (fruit size, flavor, etc.) to determine seed or breeding stock, students intuitively grasp the concept of evolution of enhanced types by artificial selection for desirable traits.

Utah science standards also call for students to cite evidence for changes in populations over time using concepts of evolution as an explanation. We approach this first by emphasizing the functional importance of genetic variation in agricultural commodities using examples of the corn leaf blight of 1970 in which mitochondrial genetic uniformity contributed to crop failure and subsequent economic losses. We also show how knowledge of evolutionary principles, such as phylogeny and biogeography, can be used as tools to predict the existence and location of pathogen resistance alleles that through breeding or genetic engineering can be used to produce improved crops. Another example we provide that emphasizes evidence of changes in genetic traits is the evolved resistance to agricultural pesticides. Classic examples involve the rapid evolution of insect resistance to petrochemicals and the potential for evolved insect resistance to genetically engineered plants such as Bt-corn or weed resistance to widely used herbicides such as glyphosate (Roundup ${ }^{\circledR}$ ). Focusing on the detrimental effects of failing to acknowledge evolutionary mechanisms in this process, we also take this opportunity to show that current agricultural management plans incorporate evolutionary principles, such as maintaining refuges of non-engineered plants to allow for some non-resistant insects to survive and maintain susceptible populations.

Finally, the objective of distinguishing between inherited and acquired traits finds an ideal example in the role that Trofim Lysenko played as head of the Soviet Ministry of Agriculture. His rejection of the modern synthesis of Darwinism and Mendelism as promoted by Nicolai Vavilov in favor of a politically motivated notion of inheritance of acquired traits, coupled with the political power he wielded, highlights the danger of failing to recognize evolutionary processes in agriculture. It also highlights the danger of allowing political or nonscientific ideology to dictate scientific practice.

Conservation The theory of evolution provides an essential framework for conserving global biological diversity, including many species that are of direct value to humans.
The concepts of descent with modification and local adaptation anchor most conservation policy today and are used to guide a wide range of conservation objectives. In this session, we examine ways that lawmakers, wildlife managers, and conservation biologists apply the theory of evolution in conservation practice.

The most basic use of evolutionary theory in conservation biology is to identify appropriate conservation units for protection and recovery. For example, the United States Endangered Species Act dictates that only species, or distinct population segments of species, are eligible for consideration under the law (Fay and Nammack 1996). How we delineate these conservation units relies on evolution in two key ways. First, molecular phylogenies (evolutionary trees) are used to evaluate the degree of genetic isolation among candidate conservation units (e.g., Moritz 1994; Crandall et al. 2000; Johnson et al. 2004). Second, evolutionary divergence for ecologically relevant phenotypes is used to evaluate the extent to which conservation units are adapted to local selective conditions. Combined, these two criteria can be used to test the hypotheses that conservation units are distinct and therefore warrant individual consideration under the law (Crandall et al. 2000; Rader et al. 2005; DeWeerdt 2006). Measures of phylogenetic diversity derived from evolutionary trees are also used to determine which species, or which geographic areas, should have the highest priority for protection (Faith 1992; Rodrigues and Gaston, 2002). Such data are especially useful when there are limited resources available for conservation efforts, or when management actions must follow a triage approach (Vane-Wright et al. 1991). We illustrate these concepts in this session with several case studies as well as a hypothetical scenario where teachers use a phylogeny to identify geographic areas that have the highest levels of phylogenetic diversity.

An understanding of natural selection is also used to guide recovery planning for rare and threatened species. Most students are aware that in some cases, it is necessary to use captive breeding programs to augment dwindling numbers of endangered species - California condor, blackfooted ferrets, scimitar-horned oryx, and several other taxa have benefited from such efforts (Wisely et al. 2003; Alagona 2004; Russello and Amato 2007). However, failure to create natural selective environments in captivity can undermine the success of reintroduction efforts. Pacific salmon reared in traditional hatcheries illustrate the problem: hatchery fish show much lower fitness than their natural counterparts (Fleming 1994, 1995). Consequently, fishery biologists are considering "conservation hatcheries" to more closely mimic natural selective environments with the hope of increasing success rates of captive-bred fish to survive and reproduce in the wild. Similarly, scientists overseeing captive breeding programs recognize that 
allowing individuals to choose their own mates based on evolved mating preferences may be superior to human efforts to identify compatible pairings (Wedenkind 2002; Roberts and Gosling 2004). The overlying theme from this body of work is clear - conservation efforts are intimately linked to the theory of evolution; failure to include these links could potentially jeopardize our ability to protect and utilize the vast store of biological diversity available in the world today. The emphasis in this session is on the potential cost of ignoring evolution in conservation decisions: these costs include failing to recognize distinct species for protection, unintentionally creating artificial selection pressures that undermine species recovery, and spending limited conservation funds aimlessly rather than using an evolutionary framework to guide judicious use of resources.

\section{Demystifying Darwin}

Several misconceptions exist about Charles Darwin. Too often, he is venerated by biologists and demonized by others. During the lunch hour of our workshop, we discuss the life and history of Charles Darwin. Our purpose is to help teachers understand the historical framework of evolutionary theory and see why Darwin was the right person, in the right place, at the right time to propose a natural explanation for the diversity of life on earth. We make it clear that Darwin himself was cautious in bringing forth the concept of natural selection and expended great effort to avoid controversy and social conflict. Hence, those who cast him as one trying to undermine religion or social order do so unfairly. Here, we outline the key elements included in our Darwin presentation and highlight ideas that teachers might include in their courses.

In this presentation, we take a historical perspective on Darwin's life using his journals, notebooks, and scientific writings to demonstrate the process of discovery that led to his most important ideas. In the famous opening paragraph of The Origin, Darwin tells us that it was during his tenure as naturalist on board H.M.S. Beagle (1831-1836) that he discerned patterns in the distribution of animals which suggested that species had not all been created in the nottoo-distant past by special creation but that novel species have appeared throughout Earth's history by means of a natural, ongoing process. He goes on to explain that upon his return to England, he determined to patiently accumulate and reflect upon all sorts of observations and facts that might confirm his proposal and, more importantly, reveal exactly what the nature of that process might be.

Darwin describes three formative periods in his scientific development: (1) the events leading to his selection as ship's naturalist; (2) the patterns of biological diversity that he saw in South America and in the Galapagos islands; and (3) the gestation of the hypothesis of natural selection, most of which took place after he married Emma Wedgwood and settled at Down House in Kent. Key aspects of young Charles' childhood and adolescence include his birth on February 12, 1809 into a wealthy upper middle class family that demonstrated liberal political (Whig) and religious (Unitarian) leanings, the death of his mother Susannah when he was eight, 2 years of medical school at the University of Edinburgh, and training for the Anglican clergy at Christ's College Cambridge. Through all of this, Darwin demonstrated a keen appreciation of nature and an innate curiosity about the living world. At Cambridge, the botanist Reverend John Stevens Henslow recognized and cultivated this curiosity, eventually paving the way for his young protégé to be included on the manifest of the Beagle. When the Beagle left England on December 27, 1831, Cambridge-trained Darwin was a creationist and admirer of William Paley's Natural Theology. It would not be long, however, before currents of discovery drew the young naturalist from his creationist moorings into uncharted and uncertain waters.

Darwin's philosophical orientation changed by degrees. Stranded shell beds on the island of St. Jago and a close encounter with a devastating earthquake in Chile convinced him that Charles Lyell's newly minted uniformitarian geology adequately explained the evolution of landscapes. The biogeography of flightless birds, finches, and fossils suggested that species populating those landscapes, as well as the underlying strata, likewise evolved. Interestingly, it was not in the tropical jungles of Brazil, with their attendant diversity, that the cracks in Darwin's creationist view began to appear but rather on the relatively desolate plains and sea cliffs of Argentina. The northern Pampas were home to a large flightless bird known as the greater rhea, with which Darwin became acquainted on his cross-country journeys with Argentinean gauchos. These same gauchos told stories of a lesser rhea populating the plains farther south in Patagonia. Darwin later encountered one of these lesser rheas in the cooking pot of his camp. Upon discovering that he and his mates were dining on one of the long-sought lesser rheas, he gathered the partial remains and added them to his collections. It seemed curious to Darwin that closely allied varieties of the same bird would occur in neighboring regions. In low sea cliffs at Punta Alta, Darwin unearthed remains of several extinct mammals that had modern counterparts in the ground sloths and armadillos of Argentina. In the rheas, he saw closely allied species replacing one another in space. In the fossils, he saw allied species replacing one another in time. Neither Paley's Natural Theology nor Darwin's creationist view said anything about replacement. Perhaps biological creation did not happen all at once as suggested by the creationist paradigm, but over a long period of geological time. Perhaps the process of biological creation was continuing 
still. If so, he reasoned that... "This wonderful relationship in the same continent between the dead and the living will throw more light on the appearance of organic beings on our Earth...and their disappearance from it, than any other class of facts."

Darwin's collections from the Galapagos archipelago further undermined his confidence in the stability of species. As in Argentina, genealogy (descent with modification) seemed to explain the distribution and diversity of life on these recently formed volcanic islands more reasonably than did special creation. He later summarized the significance of the Galapagos collections as follows..."It is the circumstance that several of the islands possess their own species of the tortoise, mockingthrush, finches, and numerous plants that strikes me with wonder. Both in space and time we seem to be brought somewhat nearer that great fact, $\ldots$ that mystery of mysteries, $\ldots$ the first appearance of new beings on this Earth." En route to England from the Galapagos in 1836, Darwin opened the first of his notebooks on transmutation, unwittingly beginning a research program that would consume the next 23 years of his life and result in publication of The Origin of Species.

On October 2, 1836, the 5-year Beagle adventure came to an end. Darwin's new career as Victorian naturalist and reluctant revolutionary, however, was just beginning. Embraced initially by the British scientific intelligentsia, supported by the family money (augmented by his marriage to his cousin Emma Wedgwood) and driven by curiosity, Darwin began to patiently accumulate and reflect "upon all sorts of facts which could possibly have any bearing" on explaining the mystery of mysteries. By 1837, Darwin confided to his notebook that he finally had a theory by which to work. That theory, greatly influenced by Reverend Thomas Malthus' writings on population dynamics and Darwin's own work with local breeders, he called natural selection. In a nutshell, evolution by means of natural selection hypothesized that (1) new species arose as a product of descent with modification as governed by environmental pressures and (2) that all species, living and extinct, are related to one another. The seeds of the evolutionary tree planted in the young naturalist's fertile mind in South America began to take root in England.

Testing of the nascent hypothesis took place at Down House, a property acquired by Charles and Emma in 1841 . The house grew commensurate with the growth of the family. Emma bore ten children, three of whom died in childhood. Down House transformed into an intellectual factory with experiments on pigeon breeding, barnacle taxonomy, seed germination, plant breeding, orchids, and worms being conducted in Darwin's coops, greenhouse, orchard, and yard. Down House also became the hub of a postal web that eventually reached around the world, that sent out requests for information from Darwin, and that conveyed answers and specimens back to him. All of Darwin's various and varied experiments and correspondences were aimed at one goal: to see if the process of natural selection could adequately account for patterns across the biological spectrum, including patterns emerging from the fields of embryology, biogeography, plant and animal physiology, plant and animal breeding, and paleontology. The answer in most cases was yes. Darwin's ongoing work, along with poor health, delayed publication until 1859 when a threat to priority from Alfred Russel Wallace finally forced Darwin's hand. Darwin authored six editions of The Origin before his death and burial in Westminster Abbey in 1882. The book and its central theorem are significant because they brought biology into the realm of science and changed the way we as humans view our own place in nature. Evolution by means of natural selection, although enhanced by findings in the later fields of genetics and developmental biology, remains central to the philosophy and practice of modern evolutionary biology.

\section{Integrating Evolution Across the Curriculum}

In his now classic article "Nothing in Biology Makes Sense Except in the Light of Evolution" written for The American Biology Teacher, Dobzhansky (1973) argued that all disciplines in biology are best understood in the context of the theory of evolution. The implication for science teachers is that any topic in the biology curriculum could potentially be explored against an evolutionary backdrop. This presents an exciting opportunity to integrate evolution throughout a biology course, as opposed to discussing it as a single unit for study usually covered at the end of the school year. As part of our workshop, we demonstrate ways that the Utah science standards in biology and earth sciences can be presented in an evolutionary framework. Our point in doing so is to help teachers think more broadly about ways to explore the theory of evolution as an explanatory framework for biological pattern. Here, we provide a few examples of how this can be accomplished.

State Science Standards The Utah State Board of Education has a clear position statement on evolution (http:// www.schools.utah.gov/curr/sci/evolution.htm). It recognizes the theory of evolution as a unifying concept in science and states that viewing present-day organisms as products of evolution provides the most productive framework for investigating and understanding their structure and function. The Utah Science Core Curriculum in Biology is even more specific about links between evolution and present-day biodiversity, calling for students to understand adaptation and natural selection, speciation, origins of genetic variation, transitional fossils, and phylogenetic 
reconstruction, among several other important topics in evolutionary biology. In our workshop, we highlight several of the standards and objectives outlined in this core curriculum and provide examples that teachers could use in their own classrooms. Here, we provide brief summaries on breakout sessions we lead focused on classification and phylogeny reconstruction, on evolution evidenced through human genetics, and on the evolution of human form and function.

Classification and Phylogeny Reconstruction A key standard in the Utah biology curriculum is to understand that biological diversity is a result of evolutionary processes. To demonstrate proficiency with this standard, students must be able to classify organisms into a hierarchy of groups based on similarities that reflect their evolutionary relationships. Such "tree thinking" is critical to several applications of evolutionary theory. Consequently, we offer a breakout session with teachers, demonstrating several hands-on approaches to teaching phylogeny reconstruction. These sessions begin with the bold statement that evolution produces patterns in nature that can be used to generate classifications and that the resulting classifications can be used to resolve important biological questions, like, "Which came first, the chicken or the egg?" Participants are then provided with a simple illustration of the mechanics of phylogenetic reconstruction that resolves the origin of scales, hair, and amnion. Pencil and paper in hand, participants are then paired up and provided with a plastic bag containing a handful of plastic animals, or a box of invertebrate fossils, with the charge of reconstructing their phylogenetic relationships. They sort the specimens on their desks and then build a phylogenetic tree, complete with tick marks at the nodes to denote synapomorphies, or, as we clarify, the arguments they use to support their hypotheses. Although the exercise does lend itself to teaching some of the important synapomorphies that unite clades of actual organisms, at this point we encourage the participants not to worry whether they have correctly identified synapomorphies but to focus instead on the logic of the exercise using whatever characters come to mind. After it appears that a few groups have correctly completed a tree, we ask volunteers to come up one at a time to the chalkboard and reconstruct their tree and character arguments (synapomorphies). If enough time is allowed, the discussion naturally turns to the real tree of life, homology, and the dynamic nature of natural classifications.

Understanding Evolution Through Human Morphology and Genetics One way to integrate the theory of evolution into the biology and earth science curricula is to focus on recent advances in our understanding of human evolution. Students are naturally interested in concepts that have direct links to themselves, and examining the human body and human genetics in an evolutionary framework is a powerful way of teaching evolution. Hence, in our workshop, we offer two sessions that deal directly with human evolution. The first focuses on human morphology and includes a review of the hominin fossil record as well as recent work on human form and function. We bring several sets of fossil skull casts that teachers can handle to see phenotypic variation in the fossil record over time. We briefly describe the history of these fossil finds, putting each into an appropriate historical context. We emphasize patterns of congruence between fossil data and the genetic data, including age estimates based on radiometric dating relative to genetic molecular clocks. We also spend time exploring several recent studies that help explain morphological traits in modern humans, including links between morphology and other unique human traits. For example, recent work by Bramble and Lieberman (2004) suggests that several human anatomical and physiological characteristics appear to be adaptations to facilitate long-distance running. Another effective example highlights recent work that links human mouth and throat morphology to the evolution of articulate speech. What these studies have in common is that they focus on the evolution of human traits likely to be of interest to students: body form, physical activity, and the ability to talk are of interest to most teenagers.

We also explore evidence for human evolution through molecular genetic data. The molecular evidence of human evolution is now massive, to the point that it can now be justifiably said that there is more evidence for evolution of humans than for any other species (Fairbanks 2007). The human, chimpanzee, and rhesus macaque genomes offer abundant and remarkable insights into human evolution in general, as well as the evolution of several human traits, including human diseases and genetic disorders (International Human Genome Sequencing Consortium 2004; Chimpanzee Sequencing and Analysis Consortium, 2005; Rhesus Macaque Genome Sequencing and Analysis Consortium 2007). In our presentation, we highlight the molecular evidence that human chromosome 2 arose from a fusion between two chromosomes that have remained separate in the great apes (Ijdo et al. 1991), the evolution of human transposable elements and their relationship to cancer and genetic disorders (Sawada et al. 1985; Ivics et al. 1997), how human pseudogenes arose through retrotransposition and evolutionary decay of functional gene copies, and how scurvy in humans is a consequence of gene decay (Torrents et al. 2003; Inai et al. 2003; Fairbanks and Maughan 2006), the molecular evidence of natural selection in humans especially as it relates to human disease (Wildman et al. 2003; Martin et al. 2005), and the molecular evidence of ancient dispersals of humans 
throughout the world from a sub-Saharan African origin (Wells 2006).

\section{Challenges to Teaching Evolution}

We end our workshop with a discussion focused on current challenges to teaching evolution in Utah public schools. We invite teachers to share their own experiences. One recurring theme is that teachers feel pressure to present the theory of evolution as an idea in crisis. Some teachers also feel pressure to introduce non-scientific alternatives to evolution into their classrooms. This pressure is often cloaked in the term "teach the controversy." In response, we point to the Utah State Office of Education statement on evolution to clarify the disciplinary bounds of science instruction by Utah teachers. We also explore the Kitzmiller v. Dover School Board court decision where science teachers in Pennsylvania were to introduce intelligent design philosophy into the biology curriculum. The intended outcome of this final session of our workshop is for teachers to return to their schools empowered with a clear charge to teach quality science and to promote outstanding scientific inquiry skills in their students.

\section{Synthesis and Recommendations}

Although our efforts have focused specifically on evolution education in Utah, our approach is sufficiently flexible for application in several outreach contexts. Our experience has taught us several key lessons. First, even a modest effort to create a partnership between university professors, local school district leaders, and teachers can result in important outcomes. Although all players in the partnership are important, an essential link is the science education professor at the university - these individuals are well connected to the public education system and often in the best position to facilitate participation by school district members in the workshops; they also have direct access to professors in biology and geology willing to be involved.

Second, involving school district leaders and school boards in the workshop strengthens evolution education for students. We have found that most public school teachers are enthusiastic about teaching evolution and desire to appropriately integrate it into their biology and earth science curricula. However, some of them shy away-even avoiding use of the word evolution in class-because they struggle with the social dynamics that sometimes attend teaching evolution, including questions from students, parents, and even administrators about the appropriateness and relevance of the topic. By bringing school district leaders into the discussion, we are able to collectively and candidly discuss these issues. In most cases, district leaders come away with a clearer understanding of the importance of teaching the theory of evolution; they are also able to articulate their district policies to teachers regarding questions that deal with religion or personal beliefs (e.g., Utah Administrative Rule R277-105). This dialogue puts teachers at ease because they know that their district leadership expects them to teach the state science standards.

Finally, we have been overwhelmed by the excitement with which public school teachers embrace recent advances in evolutionary biology. One challenge teachers face is finding time to gather new information that they can use in their biology and earth science instruction. Workshops such as ours provide a vital link between contemporary research and transmitting this information to young learners. University faculty members should see opportunities such as this not just as a form of academic service but also as a social investment that will advance science by creating a motivated and scientifically literate body of students. Some of these students will become the next generation of scientists soon to join the university, government, or private industry research communities. However, the vast majority will become the informed public that will support scientific pursuits, along with attendant benefits to humankind. For school district leaders, public school teachers, and university professors, dedication to this ultimate outcome is one well worth pursuing.

Acknowledgments The Utah Evolution Education Program is supported by a grant from the Utah State Office of Education. We thank the many school board members, school district leaders, and especially teachers who have participated in the program, and we recognize the value of their work in shaping our most prized resourceour children.

\section{References}

Abbott A. Evolutionary medicine: a model for medical school introduction. Med Educ. 2006;40:471-2.

Alagona PS. Biography of a "feathered pig": the California condor conservation controversy. J Hist Biol. 2004;37:557-83.

Ayala FJ. Darwin's gift to science and religion. Washington, DC: John Henry; 2007.

Bramble DM, Lieberman DE. Endurance running and the evolution of Homo. Nature. 2004;432:345-52.

Branch G, Scott EC. Overcoming obstacles to evolution education: in the beginning. Evolution: Education and Outreach. 2008;1:53-5.

Chimpanzee Sequencing and Analysis Consortium. Initial sequence of the chimpanzee genome and comparison with the human genome. Nature. 2005;437:69-87.

Collins FS. The language of God: a scientist presents evidence for belief. New York, NY: Free Press; 2006.

Crandall KA. The evolution of HIV. Baltimore, MD: Johns Hopkins University Press; 1999.

Crandall KA, Bininda-Emonds ORP, Mace GM, Wayne RK. Considering evolutionary processes in conservation biology: returning to the original meaning of evolutionary significant units. Trends Ecol Evol. 2000;15:290-5. 
de Oliveira T, et al. Molecular epidemiology-HIV-1 and HCV sequences from Libyan outbreak. Nature. 2006;444:836-7.

DeWeerdt S. What really is an evolutionarily significant unit? The debate over integrating genetics and ecology in conservation biology. Conserv Pract. 2006;3:10-19.

Dobzhansky T. Nothing in biology makes sense except in the light of evolution. Am Biol Teach. 1973;35:125-9.

Ewald PW. Transmission modes and the evolution of virulence: with special reference to cholera, influenza and AIDS. Human Nat. 1991;2:1-30.

Fairbanks DJ. Relics of Eden: the powerful evidence of evolution in human DNA. Amherst, NY: Prometheus Books; 2007.

Fairbanks DJ, Maughan PJ. Evolution of the NANOG pseudogene family in the human and chimpanzee genomes. BMC Evol Biol. 2006;6:12.

Faith DP. Conservation evaluation and phylogenetic diversity. Biol Conserv. 1992;61:1-10.

Fay JJ, Nammack M. Policy regarding the recognition of distinct vertebrate segments under the Endangered Species Act. Fed Regist. 1996;61:4722.

Feinberg W. The moral responsibilities of public schools. In: Goodlad JI, Soder R, Sirontnik KA, editors. The moral dimensions of teaching. San Francisco, CA: Jossey-Bass; 1990.

Fenstermacher GD. Some moral considerations on teaching as a profession. In: Goodlad JI, Soder R, Sirontnik KA, editors. The moral dimensions of teaching. San Francisco, CA: Jossey-Bass; 1990.

Fitch WM. Evolution is a fact. In: Cracraft J, Bybee RW, editors. Evolutionary science and society: educating a new generation. Colorado Springs, CO: Biological Sciences Curriculum Study; 2005. p. 22-4.

Fleming IA. Captive breeding and the conservation of wild salmon populations. Conserv Biol. 1994;8:886-8.

Fleming IA. Reproductive success and the genetic threat of cultured fish to wild. Pp. 117-135 in D. P. Philipp, ed. Protection of aquatic biodiversity. Oxford \& IBH Publishing Co. Pvt. Ltd; 1995.

Gepts P. Plant and animal domestication as human-made evolution. In: Cracraft J, Bybee RW, editors. Evolutionary science and society: educating a new generation. Colorado Springs, CO: Biological Sciences Curriculum Study; 2005. p. 180-6.

Goodlad JI, Mantle-Bromley C, Goodlad SJ. Education for everyone: agenda for education in a democracy. San Francisco, CA: JosseyBass; 2004

Ijdo JW, Baldini A, Ward DC, Reeders ST, Wells RA. Origin of human chromosome 2: an ancestral telomere-telomere fusion. Proc Natl Acad Sci U S A. 1991;88:9051-5.

Inai $\mathrm{Y}$, Ohta $\mathrm{Y}$, Nishikimi $\mathrm{M}$. The whole structure of the human nonfunctional L-gulono-gamma-lactone oxidase gene- the gene responsible for scurvy - and the evolution of repetitive sequences theron. J Nutr Sci Vitaminol. 2003;49:315-9.

International Human Genome Sequencing Consortium. Finishing the euchromatic sequence of the human genome. Nature. 2004;431: 931-45.

Ivics Z, Hackett PB, Plasterk RH, Izsva Z. Molecular reconstruction of Sleeping Beauty, a Tc1-like transposon from fish, and its transposition in human cells. Cell. 1997;91:501-10.

Johnson JB, Dowling TE, Belk MC. Neglected taxonomy of rare desert fishes: congruent evidence for two species of leatherside chub. Syst Biol. 2004;53:841-54.

Martin MJ, Rayner JC, Gagneux P, Barnwell JW, Varki A. Evolution of human-chimpanzee difference in malaria susceptibility: relationship to human genetic loss of $\mathrm{N}$-glycolyl-neuraminic acid. Proc Natl Acad Sci U S A. 2005;102:12819-24.
Metzker ML, et al. Molecular evidence of HIV-1 transmission in a criminal case. Proc Natl Acad Sci U S A. 2002;99:14292-7.

Mindell DP. Evolution helps solve crimes. In: Cracraft J, Bybee RW, editors. Evolutionary science and society: educating a new generation. Colorado Springs, CO: Biological Sciences Curriculum Study; 2005. p. 175-179.

Moritz C. Defining evolutionarily significant units for conservation. Trends Ecol Evol. 1994;9:373-5.

National Academy of Sciences (U.S.). Science and creationism: a view from the National Academy of Sciences. National Academy Press, Washington, DC. 1999.

National Academy of Sciences (U.S.) and Institute of Medicine (U.S.). Science, evolution, and creationism. National Academies Press, Washington, D.C. 2008.

Nesse RM, Stearns SC, Omenn GS. Medicine needs evolution. Science. 2006;311:1071.

Nesse RM, Williams GC. Why we get sick: the new science of Darwinian medicine. Times Books, New York. 1994.

Palumbi SR. Humans and the world's greatest evolutionary force. Science. 2001;293:1786-90.

Pew Forum on Religion and Public Life. 2008. U.S. Religious Landscape Survey: religious beliefs and practices: diverse and politically relevant. Washington, DC: Pew Research Center.

Public Law 107-110. 2001. No Child Left Behind Act of 2001. United States 107th Congress.

Rader RB, Belk MC, Shiozawa DK, Crandall KA. Empirical tests for ecological exchangeability. Anim Conserv. 2005;8:239-47.

Rhesus Macaque Genome Sequencing and Analysis Consortium. Evolutionary and biomedical insights from the rhesus macaque genome. Science. 2007;316:222-34.

Roberts SC, Gosling LM. Manipulation of olfactory signaling and mate choice for conservation biology: a case study of harvest mice. Conserv Biol. 2004;18:548-56.

Rodrigues ASL, Gaston KJ. Maximising phylogenetic diversity in the selection of networks of conservation areas. Biol Conserv. 2002; 105:103-11.

Russello MA, Amato G. On the horns of a dilemma: molecular approaches refine ex situ conservation in crisis. Mol Ecol. 2007; 16:2405-6.

Sawada I, Willard C, Shen CK, Chapman B, Wilson AC, Schmid CW. Evolution of the Alu family repeats since the divergence of human and chimpanzee. J Mol Evol. 1985;22:316-22.

Stearns SC. Issues in evolutionary medicine. Am J Human Biol. 2005; 17:131-40.

Torrents D, Suyama M, Zdobnov E, Bork P. A genome-wide survey of human pseudogenes. Genome Res. 2003;13:2559-67.

Vane-Wright RI, Humphries CJ, Williams PH. What to protect? Systematics and the agony of choice. Biol Conserv. 1991;55:23554.

Wedenkind C. Sexual selection and life history decisions: implications for supportive breeding and management of captive populations. Conserv Biol. 2002;16:1204-11.

Wells S. Deep ancestry: inside the genographic project. Washington, DC: National Geographic Society; 2006.

Wildman DE, Uddin M, Liu G, Grossman LI, Goodman M. Implications of natural selection in shaping $99.4 \%$ nonsynonymous DNA identity between humans and chimpanzees: enlarging the genus Homo. Proc Natl Acad Sci U S A. 2003;100:73840.

Wisely SM, McDonald DB, Buskirk SW. Evaluation of the genetic management of the endangered black-footed ferret (Mustela nigripes). Zoo Biol. 2003;22:287-98. 